\title{
Carbon risk real estate monitor: making decarbonisation in the real estate sector measurable
}

\author{
Maximilian M. Spanner
Kompetenzzentrum für Nachhaltigkeit in der Immobilienwirtschaft,
International Real Estate Business School, \\ Maximilian M. Spanner
Kompetenzzentrum für Nachhaltigkeit in der Immobilienwirtschaft,
International Real Estate Business School, \\ Maximilian M. Spanner
Kompetenzzentrum für Nachhaltigkeit in der Immobilienwirtschaft,
International Real Estate Business School, \\ University of Regensburg, Regensburg, Germany, and \\ Julia Wein
IIÖ-Institute for Real Estate Economics, Wörgl, Austria \\ Julia Wein
IIÖ-Institute for Real Estate Economics, Wörgl, Austria
}

\begin{abstract}
Purpose - The purpose of this paper is to investigate the functionality and effectiveness of the Carbon Risk Real Estate Monitor (CRREM tool). The aim of the project, supported by the European Union's Horizon 2020 research and innovation program, was to develop a broadly accepted tool that provides investors and other stakeholders with a sound basis for the assessment of stranding risks.

Design/methodology/approach - The tool calculates the annual carbon emissions (baseline emissions) of a given asset or portfolio and assesses the stranding risks, by making use of science-based decarbonisation pathways. To account for ongoing climate change, the tool considers the effects of grid decarbonisation, as well as the development of heating and cooling-degree days.

Findings - The paper provides property-specific carbon emission pathways, as well as valuable insight into state-of-the-art carbon risk assessment and management measures and thereby paves the way towards a low-carbon building stock. Further selected risk indicators at the asset (e.g. costs of greenhouse gas emissions) and aggregated levels (e.g. Carbon Value at Risk) are considered.

Research limitations/implications - The approach described in this paper can serve as a model for the realisation of an enhanced tool with respect to other countries, leading to a globally applicable instrument for assessing stranding risks in the commercial real estate sector.

Practical implications - The real estate industry is endangered by the downside risks of climate change, leading to potential monetary losses and write-downs. Accordingly, this approach enables stakeholders to assess the exposure of their assets to stranding risks, based on energy and emission data.

Social implications - The CRREM tool reduces investor uncertainty and offers a viable basis for investment decision-making with regard to stranding risks and retrofit planning.

Originality/value - The approach pioneers a way to provide investors with a profound stranding risk assessment based on science-based decarbonisation pathways.
\end{abstract}

Keywords Risk management, Commercial real estate, Science-based targets, Decarbonisation, Downscaling, Carbon risk, Stranding risk, Excess emissions.

Paper type Research paper

(C) Maximilian M. Spanner and Julia Wein. Published by Emerald Publishing Limited. This article is published under the Creative Commons Attribution (CC BY 4.0) licence. Anyone may reproduce, distribute, translate and create derivative works of this article (for both commercial and noncommercial purposes), subject to full attribution to the original publication and authors. The full terms of this licence may be seen at http://creativecommons.org/licences/by/4.0/legalcode
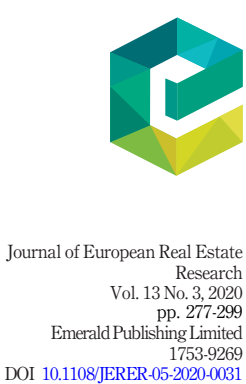


\section{JERER 13,3}

\section{Introduction}

The Paris climate agreement intends to limit global warming to below $2^{\circ} \mathrm{C}$ above the preindustrial level. This implies that greenhouse gas emissions (GHG) must peak no later than 2030, and carbon emissions originating from fossil fuels need to be suspended completely by 2070 (UN-FCCC United Nations Framework Convention on Climate Change, 2016). However, an analysis carried out by the United Nations Environmental Program (UNEP United Nations Environmental Program, 2016) indicates that current emission-reduction commitments may result in global warming of more than $3^{\circ} \mathrm{C}$, and a "business-as-usual" scenario even to a rise in temperature of more than $4^{\circ} \mathrm{C}$ by 2100 compared to the pre-industrial level.

Research conducted by the European Public Real Estate Association (EPRA) and the European Association for Investors in Non-Listed Real Estate Vehicles (INREV) show that the real estate industry is responsible for approximately $40 \%$ of energy used and $29 \%$ of all GHG emissions produced within the $E U$, highlighting the substantial responsibility devolving on this sector. Therefore, the property industry will play a key role in the decarbonisation efforts of the European Union (INREV, EPRA, 2016, 2018).

Against this high level of responsibility of the property industry, the refurbishment rates of subsisting buildings are still too low and, due to the long life cycle of buildings, most of the building stock existing in 30 years has already been built, new construction will not be able to compensate for this surplus of GHG emissions. One reason for these low rates might be that for most investors, retrofits are still driven primarily by cost-benefit analysis, whereas sustainability-related motivation seems not to play a role at all in the decisionmaking process (Christensen et al., 2018). On the other hand, barriers to more investment include - besides economic factors and split incentives - a lack of transparency regarding the risks associated with poor energy efficiency.

Aggravating the European Union's flagship in terms of climate protection efforts, the Energy Performance of Buildings Directive $(E P B D)$ which demands "nearly-zero-energy" buildings from 2021 onwards, focusses solely on some kind of emission (so-called "regulated emissions"), whereas other so-called "unregulated" emissions are not taken into account. Therefore, international investors have no comparable entity that targets all relevant emissions originating from their building stock and are likely to "get lost" in a minefield of nationally varying regulations, especially as these unregulated emissions can vary hugely, depending on the usage type.

As a survey conducted by the CRREM consortium highlights, the major players within the real estate industry already practice carbon accounting for at least Scope 1 and Scope 2 emissions. However, action-guiding effects are still lacking due to the absence of clear avoidance goals and of information, combined with a lack of carbon prices (Haran et al., 2019). The existing GHG reduction goals are aggregated at excessively high levels and a lack of small-scale data for individual properties on a national or regional level for different types of use can still be observed. This lack of transparency, combined with poor information, bears the risk of ending up in a vicious circle, and the absence of GHG reduction measures, to a risk of capital misallocation. In particular, the actors in the real estate sector require future-oriented data for a focused risk assessment and management. The current possibilities do not provide a viable long-term future outlook.

The CRREM project overcomes this lack of information by providing a tool, the Carbon Risk Real Estate Monitor (CRREM tool), that makes use of a downscaling approach which breaks down the mitigation targets to a regional and sectoral diversified level. This provides the industry with science-based decarbonisation pathways until 2050, giving them the possibility to make their assets and portfolios 1.5-/2-degree-ready ("Paris-proof portfolio"). After entering of the property-specific input data, the tool calculates the baseline emissions 
as well as their likely development and setting them in relation to the specific decarbonisation pathways, so as to determine whether or when the property may face stranding. Additionally, the tool comprises various simulation possibilities like "virtual" retrofit decisions and their consequences on ecological performance.

The main objective of this paper is to describe the CRREM tool and its functionalities, emphasising the added value for investors and further stakeholders. The remainder of the paper is organised as follows. Section 2 defines the concept of stranded assets and presents existing approaches for the assessment of a building's carbon performance. Section 3 explains the general conceptualisation of the CRREM and its specific understanding of risk. Section 4 describes the technical implementation of the CRREM tool and its derivation of science-based decarbonisation pathways for individual assets. Section 5 contains the functional implementation of the CRREM tool and shows what kind of building data needs to be entered by the user and provides a first graphical and numerical assessment. Additionally, this Section introduces user options to make various assumptions of their own. Section 6 presents the results of the risk assessment with respect to financial implications and the simulation of future retrofit measures. Section 7 concludes and provides a further outlook for potential extensions of the CRREM tool.

\section{Background}

\subsection{Need for carbon risk assessment}

Research on the impact of climate change on the real estate industry has gained more and more attention in the past years. However, up to now, existing research efforts have focussed almost solely on the potential upside risks of climate change in terms of financial payback, green pay-offs or a green premium from higher returns, reduced operating costs or competitive advantages (Eichholtz et al., 2009; Fuerst and Mc. Allister, 2011a; Bienert, 2016) [1].

For example, Robinson $e t$ al. found that a green pay-off is usually associated with higher energy efficiency or other sustainability-related aspects of a property, and the willingnessto-pay for such green office buildings was highest for publicly traded firms and companies in the energy- and information technology (IT)-industry. Especially energy-efficient lighting, efficient electrical and gas heating and cooling are the most broadly accepted and preferred features in the USA (Robinson et al., 2016a). Various studies have found that eco-labels such as leadership in energy and environmental design (LEED) certification enhance property performance and add value in terms of higher rents and sales prices (Eichholtz et al., 2010; Fuerst and Mc. Allister, 2011a, 2011b; Kok and Jennen, 2012; Hui et al., 2015) as well as higher hotel revenues (Robinson et al., 2016b).

According to Hui et al., LEED certified office buildings in Shanghai, China were found to have a premium of $12.8 \%$ on the rental levels compared to non-certified buildings (Hui et al., 2015). Suh et al. investigated the office market in New York City and found that LEED and/ or EnergyStar certification even positively influences the market values of adjoining buildings (Suh et al., 2019). By contrast, no similar effect was found for LEED neighbourhood certifications (Freybote $e t$ al., 2015). Nonetheless, these positive impacts have not generally translated into more sustainable investments and retrofits, and this is a major issue in the contemporary environment.

When it comes to downside risks, existing research approaches focus predominantly on natural hazards and extreme weather events (Bouwer, 2010; Gasper et al., 2011; Bienert, 2014; Hirsch et al., 2015) or rising sea-levels and the threats of climate change to coastal cities (Hallegatte et al., 2011; Balica et al., 2012; Hallegatte et al., 2013; McAlpine and Porter, 2018; Conyers et al., 2019; Walsh et al., 2019).
Carbon risk real estate monitor 
JERER 13,3

280
Figure 1.

Concept of stranding in the real estate sector
In contrast, no sufficient focus has been laid on the fact that ongoing climate change might endanger the business case of real estate companies and consequently, the issue of "stranded" assets has attracted only minor attention.

According to Caldecott, this term which originates from the oil and coal industry indicates that some resources which are currently taken into account in company valuation might have to be revaluated if unexpected shifts, for example demand and price declines or the introduction of a carbon tax, occur (Caldecott, 2018a; Caldecott, 2018b). Applied to the real estate industry, assets can be regarded as stranded as soon as they fail to meet future regulatory requirements and future market expectations in terms of carbon performance (Caldecott et al., 2017).

Therefore, as illustrated in Figure 1, stranding can be observed at that point in time when an asset's carbon performance in terms of GHG intensity per square meter (baseline emissions; black line) hits the maximum allowance (green graph). The only way to overcome stranding is to undertake retrofit actions (dashed arrow) and fulfil the emission target again. Ideally, the retrofit measure will be consistent with Carbon disclosure project (CDP)'s sectoral decarbonisation approach (CDP Carbon Disclosure Project, UN Global Impact, World Resources Institute, WWF, 2015), enabling long-term future-proof performance.

Given that consumers are becoming demonstrably more and more environmentally consciousness, and that governments worldwide are passing more stringent regulations, buildings that do not meet market expectations and regulatory guidelines will face a loss in value as well as write-downs and will therefore require major refurbishment activities. Hence, stranding risks need to be accorded the appropriate status in every investor's risk management process.

\subsection{Existing tools and initiative for carbon risk assessment}

Existing tools for the assessment of carbon risks either focus purely on current emissions instead of future developments and targets, are geographically limited or restricted in terms of asset classes, for example hotel carbon measurement initiative's "Hotel Footprint Tool" (WTTC, ITP - World Travel and Tourism Council, International Tourism Partnership, 2016) or hotel energy solutions (HES)' "Energy Solution Toolkit” (HES Hotel Energy Solutions, 2011). Other instruments like the "Hotel Water Measurement Initiative tool" (ITP, International Tourism Partnership, 2016), which exclusively targets a hotel property's water

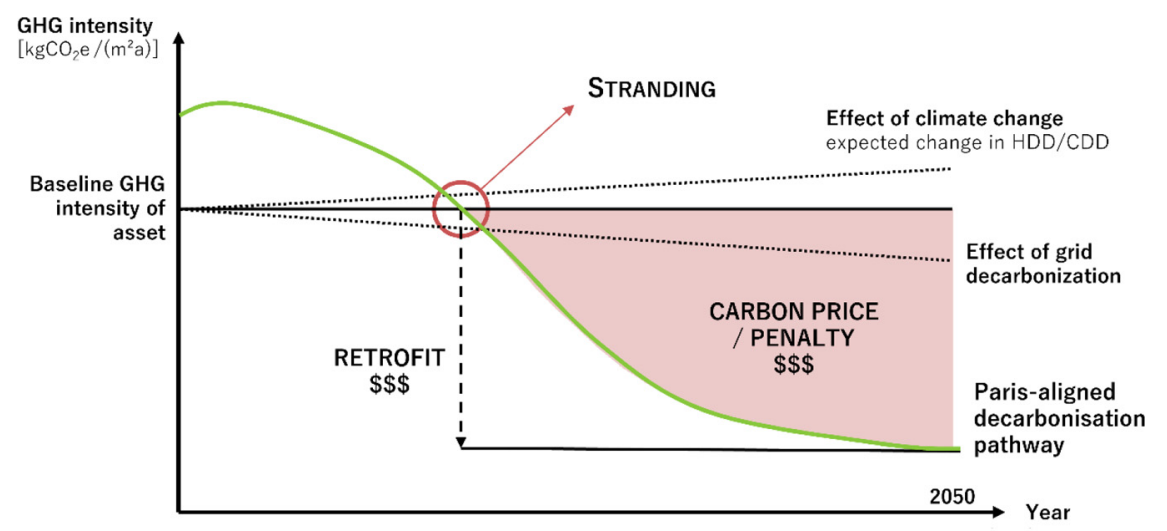

Source: Author's representation 
footprint, are also very limited in scope and methodology. Additionally, some tools have often not received any significant market acceptance and lack public recognition due to a lack of transparency.

Tools such as the Carbon Value Analyser, developed by Deutsche unternehmensinitiative energieeffizienz (DENEFF) (DENEFF Deutsche Unternehmensinitiative Energieeffizienz, Finanzforum Energieeffizienz, 2020), provide future prospects and enable an analysis with only seven input parameters for the financial assessment of climate change performance. The Carbon Value Analyser benchmarks single commercial assets against a linear reduction pathway from $2008\left(215 \mathrm{kWh} / \mathrm{m}^{2}\right)$ to $2050\left(100 \mathrm{kWh} / \mathrm{m}^{2}\right)$ according to the German energy efficiency strategy for buildings [Bundesministerium für Wirtschaft und Energie (BMWi), 2015]. A focus is placed on the financial risks and opportunities for a single asset (e.g. change in value, carbon tax and required retrofit costs), calculated from the financial effects of different policy instruments, to achieve climate and energy-related policy goals. The tool uses final energy consumption for the analysis, and the energy consumption considered is based on the definitions and accounting methods from the Energy Saving Ordinance $(E n E v)$. In contrast to the CRREM tool, restrictions include the limitation to one country and providing an assessment of the stranding risks with only one pathway for the entire commercial real estate sector. Its focus is only asset-based, meaning that an investor cannot assess a multitude of buildings or his whole portfolio at the same time. A portfolio-level analysis is also not provided. The tool certainly provides some valuable initial steps towards the assessment of carbon emissions but is not able to differentiate between different types of usage and does not include detailed reduction pathways. The Carbon Value Analyser only accounts for some basic building features and user-input in terms of energy consumption data is very limited, in fact to only one source of heating supply, no cooling and no fugitive emissions.

Ultimately, existing tools have a different focus, for example often only country-specific, orientate towards future regulatory requirements instead of science-based decarbonisation targets and provide only a short-term outlook or snapshot.

By contrast, Global Real Estate Sustainability Benchmark (GRESB)'s environmental, social and governance Benchmark is broadly accepted in the market and defines high standards with a sound methodology, but focusses only on supplying current emission figures and benchmarks against other assessment participants (best-in-class approach), instead of providing future decarbonisation pathways or stranding-risk assessment. Additionally, most participants in the GRESB assessment are already amongst the best-in-class assets, whereas other, less sustainable assets are not assessed at all. Despite the analysis of only the best-inclass, the GRESB peers on average still overperform the targets, indicating that even the best assets may not truly comply with the decarbonisation targets. Figure 2 below depicts the performance of all participants in the 2019 GRESB assessment, exemplarily for the UK office sector (blue line), against the CRREM decarbonisation requirements (green line, here according to the $1.5^{\circ} \mathrm{C}$ target). The intersect of the green and blue lines show the point of stranding; from this point onwards the $1.5^{\circ} \mathrm{C}$ target is no longer met. The percentage of GRESB assets above the GHG intensity target are shown by the red bars in the figure, also indicating the outperformance of the analysed assets. This analysis conducted by CRREM and GRESB clearly highlights the urgent need for a sound carbon risk assessment methodology and a highly effective tool.

\section{Conceptualisation of the carbon risk real estate monitor}

As outlined above, existing tools mostly set other priorities and do not offer a clear future perspective with decarbonisation pathways enabling investors not only to assess their current emissions, but also future stranding risks. Additionally, to the best of our
Carbon risk real estate monitor

281 


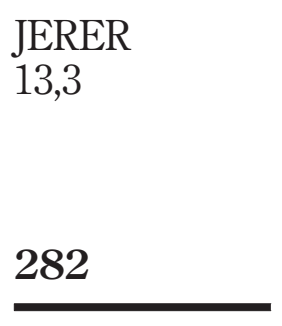

Figure 2.

Benchmarking GRESB against the CRREM $1.5^{\circ} \mathrm{C}$ decarbonisation pathways

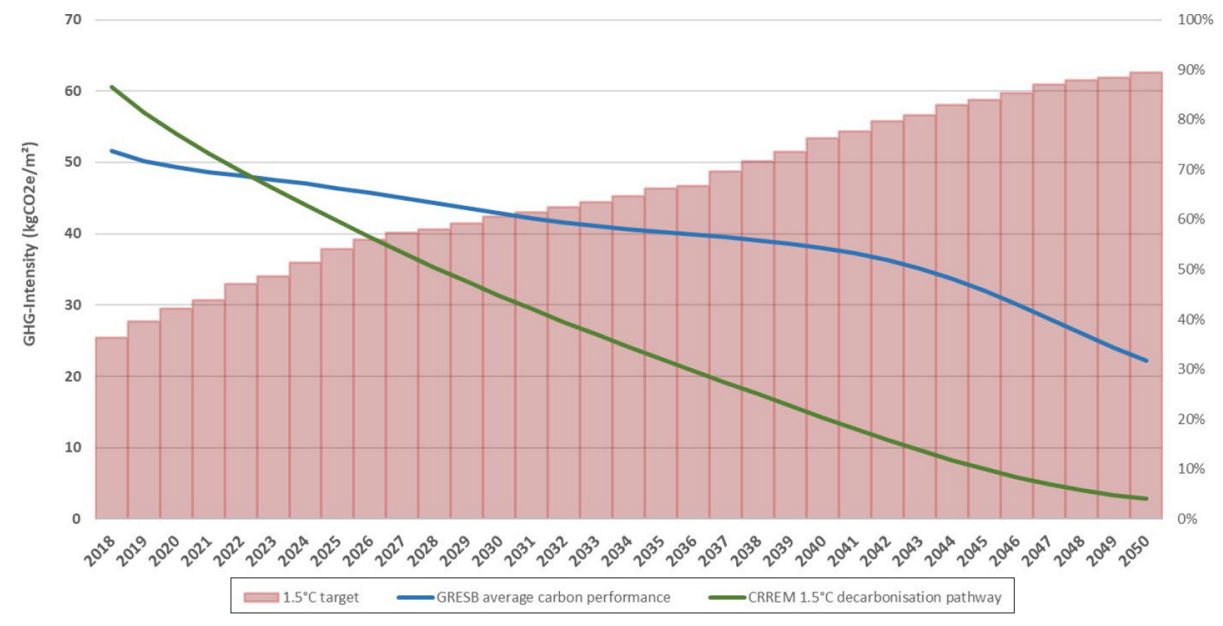

\section{Source: GRESB, CRREM}

knowledge, none of the existing tools placed a significant focus on the financial threats of high carbon emissions but only delivers an asset-snapshot. However, as identified in many stakeholder-dialogues that the CRREM team conducted, investors require broad information with respect to carbon emissions and stranding risks - both during the acquisition consultation as well as and especially while owning a property. For the purpose of adequate risk management, it is essential that all kind of emissions should be considered. For example, considering only electrical energy use would not be sufficient. Additionally, institutional investors need a tool that differentiates between usage type and location.

In summary, besides core aspects like user-friendliness and excellent functionality, a tool which is capable of assessing the carbon risks needs to comply with the following criteria to meet the needs of the property industry:

- provide science-based decarbonisation pathways for different locations and building types;

- account for different types of use and locations;

- incorporate ongoing climate change (shift in Heating Degree Days [HDD]/ Cooling Degree Days [CDD] [2]) and consider (electricity) grid decarbonisation;

- provide transparent, comprehensible and reliable calculations;

- cover all relevant emission sources including cooling and fugitive losses;

- account for property-specific anomalies and/or considerations (occupancy rate, varying reporting periods, etc.);

- enable investors to assess a multitude of properties and portfolios with only one application;

- focus on at least all European countries, while providing the option for a worldwide roll-out;

- guarantee the confidential use of user data;

- sufficient public availability; and

- ensure maximum market acceptance. 
The last-mentioned aspect, broad acceptance within the group of institutional investors and other stakeholders, would ensure that a tool defines a transparent standard for carbon risk assessment, to achieve an optimal capital allocation. With CRREM, we placed particular focus on the involvement of relevant stakeholders by implementing the so-called "European Investor Committee" (EIC) - a group of institutional investors, corporate partners, industry bodies and scientists - accompanying, supporting and advising the project and tool development. The CRREM team regularly asked for feedback and pilot-testing while developing the tool. We thereby wanted to ensure broad acceptance early on. All in all, numerous large international real estate investors tested the tool, which resulted in over four million square metres of lettable space analysed, resulting in a large geographical range and asset-mix. To date, investors and asset managers responsible for more than 3,112 billion euros of Assets under Management (AuM) have made use of the tool. User groups included institutional investors, pension funds, corporates, insurance companies, asset owners, consultants, fund-, asset and investment managers. Further industry and certification bodies provided valuable feedback through their expertise on building standards and the issue of carbon risk. The CRREM tool and decarbonisation pathways can be aligned with and incorporated as a metric for operational certificates or included in sustainability reporting. Lastly, academic research and feedback regarding the methodology and global downscaling targets was presented to various field experts.

\section{Technical implementation of the "Carbon Risk Real Estate Monitor" tool 4.1 Derivation of property-specific decarbonisation pathways}

The CRREM project has derived country and asset-class-specific decarbonisation and energy reduction pathways, following a stepwise decreasing energy consumption aligned with the requirements of the Paris Agreement to limit global warming to $2^{\circ} \mathrm{C}$ or $1.5^{\circ} \mathrm{C}$ by 2050 compared to the pre-industrial level. The CRREM pathways start with the current market average, showing that the mean is underperforming and hence is required to decrease in order not to exceed the carbon budget for the sector until 2050. CRREM estimates that the carbon-intensity of the building sector will globally have to decline from around $52 \mathrm{kgCO}_{2} \mathrm{e} / \mathrm{m}^{2} / \mathrm{yr}$ to below $10 \mathrm{kgCO}_{2} \mathrm{e} / \mathrm{m}^{2} / \mathrm{yr}$ by 2050 to comply with the 2-degree global carbon budget. These pathways can be regarded as maximum emission allowances (and refer to the green graph in Figure 1 above).

CRREM considers the climate impact of different energy sources (so-called carbon intensities) by directly benchmarking a building's carbon emissions against the CRREM decarbonisation pathways. The target figure regarding the CRREM decarbonisation pathways is a building's carbon intensity in terms of annual operational greenhouse gas emissions per gross internal floor area measured in carbon dioxide equivalent $\left(\mathrm{kgCO}_{2} \mathrm{e} / \mathrm{m}^{2}\right)$. This includes additional greenhouse gases apart from carbon dioxide. Energy-reduction targets have not been further converted, as the user should be able to use energy readings from the property bills and meters.

As in Figure 3 below, eight steps are undertaken to derive the country and buildingsector specific energy-intensity pathways. The initial starting point is the derivation of a global $\mathrm{CO}_{2} \mathrm{e}$ emissions budget consistent with the $1.5^{\circ} \mathrm{C}$ and $2^{\circ} \mathrm{C}$ warming targets and reducing this to the proportion for the real estate sector. The global $\mathrm{CO}_{2} \mathrm{e}$ emissions budget for the building sector is $191 \mathrm{GtCO}_{2} \mathrm{e}$ and $262 \mathrm{GtCO}_{2} \mathrm{e}$ for the $1.5^{\circ} \mathrm{C}$ and $2^{\circ} \mathrm{C}$ targets, respectively. The global emissions per floor area are obtained with the global trajectory of the floor area for the entire building stock. The underlying data is the global population growth, per capita-floor-space usage estimates and the increasing building stock defined by the new construction minus demolition. The carbon emissions per floor area are referred to
Carbon risk real estate monitor

283 


\section{JERER 13,3}

\section{4}

Figure 3.

Schematic overview of the CRREM downscaling methodology
Global GHG budget and emissions pathway (consistent with a certain amount of global warming)

Global buildings GHG emission pathway

Global buildings GHG intensity pathway

EU/UK buildings GHG intensity pathway

EU/UK commercial real estate (CRE) GHG intensity pathway

Country-specific CRE GHG intensity pathways

Country-specific CRE-subsector GHG intensity pathways

Country-specific CRE-subsector energy intensity pathways

\section{Source: CRREM}

as the carbon intensity, used for the calculation of the $\mathrm{CO}_{2} \mathrm{e}$ intensity pathway for the building sector. The starting point for the global intensity pathway is at $51.7 \mathrm{kgCO} 2 \mathrm{e} / \mathrm{m} 2$ in 2018. The downscaling process is continued by the derivation of the EU buildings GHG intensity pathway (including the UK building stock). To derive a country-specific and usetype-specific downscaling pathway, CRREM uses each country's baseline carbon intensity and the assumption of converging carbon intensities until 2050 to the $1.5^{\circ} \mathrm{C}$ and $2^{\circ} \mathrm{C}$ targets. CRREM also applies the SDA convergence approach in different steps of the downscaling process. This means that the overall carbon intensity of each country's building sector converges gradually towards the global average figure in the defined target year of 2050 .

In order to calculate the GHG intensity pathways for individual countries and use-types, the Sectoral Decarbonisation Approach (CDP, 2015), each country's baseline carbon intensity, as well as assumptions of converging carbon intensities at the country level (Figure 4) are used. The EU building floor area projections are based on the UN Environment and International Energy Agency (2017) global status report. The baseline of 2018 buildings GHG intensities are derived from and based on the average energy mix for each country, property type and respective emission factors. Finally, country-specific baseline end-energy intensity $\left(\mathrm{kWh} / \mathrm{m}^{2}\right)$ data is used to derive the energy-intensity pathways for individual countries and use-types. Based on projected emission factors and energy mix, typical carbon-to-energy factors have been derived, enabling the conversion of carbon-intensity to energy-intensity figures. In some cases, grid decarbonisation might progress faster than decarbonisation requirements, which results in no or minimal electricity-reduction requirements. In these cases, CRREM requires energy reductions in line with the UN Sustainable Development Goals of $2.9 \%$ per year. A more detailed description of the CRREM downscaling documentation and assessment methodology is available at: www.crrem.org/pathways (CRREM, Carbon Risk Real Estate Monitor, 2020b).

\subsection{It-Implementation}

In order to account for user-friendliness and an easily applicable, functional tool that enables assessing a multitude of properties with data from internal sources, we decided, in close consultation with the involved EIC, to conceive the "Carbon Risk Real Estate Monitor" as a standard offline MS Excel (.xlsx) file. 


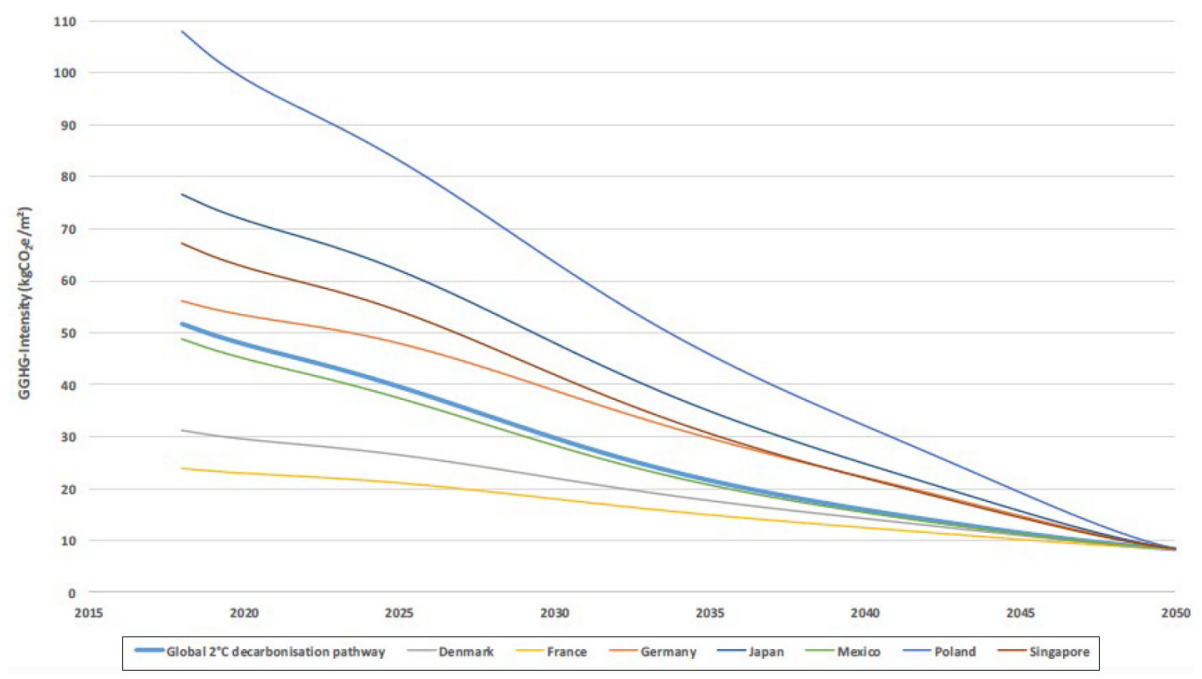

Source: CRREM
Carbon risk real estate monitor

285

Figure 4.

Convergence of carbon intensity pathways in different countries

The advantage of this structure is that no large server infrastructure or user accounts are necessary and additionally, by using a standardised office application, the user benefits from the familiar environment of a widely used office program, enabling comprehensive use after only a short period of introduction, while the requirements of the user's hardware are kept comparatively low. From an IT perspective, the wide usage of Excel and the availability for most operating systems including macOS renders the programming of different versions redundant.

Additionally, an excel-based tool instead of an online-based client server system ensures the confidentiality of user-data without the need to set any further security systems, and enables users to easily integrate the CRREM tool into their existing structures and save their evaluations on local systems.

Currently, as CRREM and GRESB have already aligned their input sheets, we are working with GRESB to integrate CRREM into their annual assessment, making the tool even more user-friendly and stranding risks more prominent within the commercial real estate sector.

\section{Functional implementation of the "Carbon Risk Real Estate Monitor" tool}

The CRREM tool allows for up to 250 properties throughout all EU-27 countries (surplus UK) at the moment and is provided for downloading without charge via www.crrem.eu/tool, where users can choose between an empty . $x l s x$ file and a prefilled version, providing some example properties and assessments. Updates, whenever necessary, will also be provided via the respective website. The tool comes with some explanatory remarks on the input sheet and additionally, some video tutorials showing the main functions of the tool, as well as a comprehensive user-guide ("CRREM Risk Assessment Reference Guide”). Additionally, users are invited to ask questions or give feedback on crrem.eu.

When opening the tool, the user will see eight different tabs ("Start", "Targets", "Input", "Asset", "Portfolio", "Settings", "Unit Converter" and "Back-end"), each clearly named and 
JERER 13,3

286

accompanied by an explanation following the easy-to-use approach. By clicking on the targets sheet, the tool displays the $1.5^{\circ} / 2^{\circ} \mathrm{C}$ decarbonisation and energy-reduction pathways derived in Section 4.1, and users can choose between different countries and types of use.

The input sheet (Figure 5) consists of six sections, asking the user to enter the propertyspecific data. Accordingly, each row refers to an individual property and each column represents a specific input variable. Data can either be entered as text, numbers or dropdown selection, depending on the variable considered. Additional validation checks are carried out in the background, informing the user if entered data is invalid (e.g. non-existent ZIP code).

Of more than 50 indicators available, the minimum number of inputs necessary to start the assessment varies between 10 and 20. To ensure the correct allocation, each asset receives an individual asset-identifier (ID) starting with "1" to "X". Moreover, the user can choose whether or not the property should be included in further assessments by selecting exclude/include.

The user is first asked to enter the general information relating to the building, such as the asset name, reporting year, Gross Asset Value (GAV), as well as information regarding the reporting year (starting date and length). The analysis is currently available for the reporting years 2018 and 2019. Later, it is necessary to account for uneven reporting periods and varying energy-consumption data. Additionally, the user can allocate the property to a certain entity/portfolio.

The second category is for building characteristics like location (incl. ZIP code), property type and - if selected, mixed-use as property type - the floor area shares of different property types, whether the asset is equipped with air conditioning and - of course - the asset size in terms of total gross internal floor area (IPMS 2 [3]), as well as (potential) vacant space. Depending on the type of use, the asset is projected against different decarbonisation pathways. Entering a ZIP code is optional, but improves the assessment accuracy, as further calculations are not aggregated to country-level, but to a more regional-level (NUTS3). CRREM differentiates between the following types of use: office, retail high street, retail shopping centre, retail warehouse, industrial/distribution warehouse, hotel, healthcare, lodging/leisure and recreation as well as mixed use. For mixed-use properties, a decarbonisation pathway based on the floor area shares is calculated.

After entering the building characteristics, the user is asked in a third step to provide energy-consumption data for the whole building. The tool separates between grid electricity, natural gas, fuel oil, district heating as well as district cooling and offers two additional fields for "other energy consumption", where the user can select (drop-down) between biogas, wood chips, wood pellets, coal, landfill gas and liquified petroleum gas (LPGs). Each amount of energy used has to be provided in $\mathrm{kWh}$. Additionally, the user needs to enter the data coverage and maximum coverage (i.e. if the given consumption data is available and applicable for the complete floor area or only parts of it, e.g. natural gas consumption only applicable for 8,000 of $10,000 \mathrm{~m}^{2}$ ).

As the tool is not only capable of dealing with emissions originating from energy consumption, but also accounts for fugitive emissions/refrigerant losses, the user is asked in a fourth step to provide data on the type of gas and amount of leakage (if applicable). The tool offers a total of 44 refrigerant gases, each with a specific global warming potential (expressed in carbon dioxide equivalents).

The fifth section focusses on renewable energy, especially, but not limited to electricity, both produced on- and off-site. The tool then differentiates between energy consumed on-site and exported. Generally, to avoid double-counting, off-site renewables do not reduce the carbon risk of individual buildings; however, only renewable electricity purchased directly 

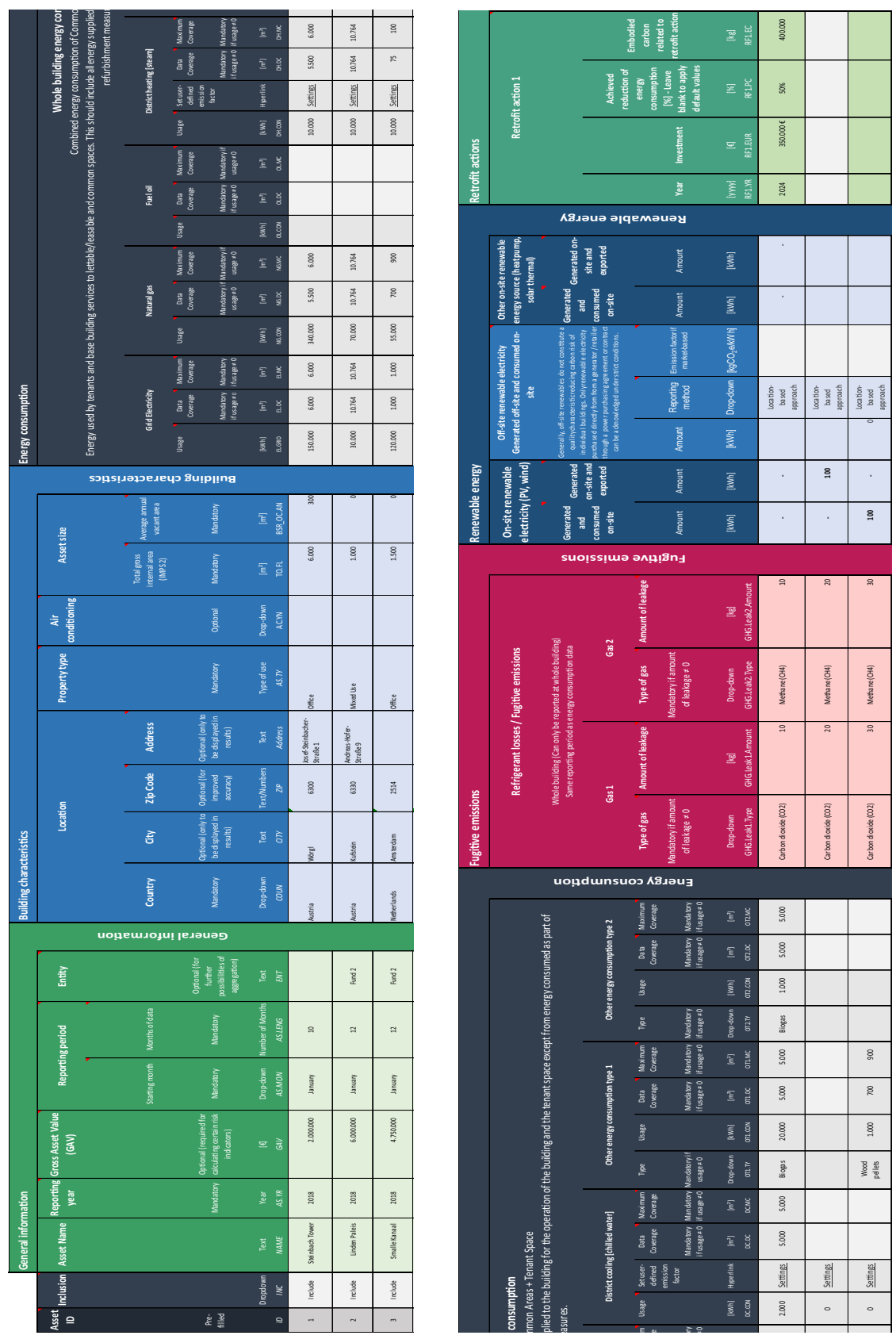

Carbon risk real estate monitor

Figure 5. CRREM Input sheet 
JERER 13,3

288

from a generator or retailer through a power purchasing agreement or contract has an impact on reducing the carbon emissions. For the scenario of renewable electricity generated but consumed on-site, the user can choose between two reporting methods: either using the location-based or market-based approach. Location-based emission factors are based on the average emission intensities of the electricity grid (national grid-averages), whereas the marked-based approach reflects the GHG emissions based on emissions by the generators from which the entity purchases electricity. Thus, either the national average or providerspecific emission factors will be considered in further calculations. The CRREM energyreduction pathways refer to the final energy (actual energy from e.g. utility bills), differing from primary energy which indicates how much energy is needed, for example, by burning fossil fuels. The net energy demand of an asset is considered to calculate the reduction pathway, meaning that energy imports and exports is not identical to the energy consumption of the property. Two different approaches are available with regard to the net energy demand relating to parameters like procurement, consumption, generation and export, as illustrated in Figure 6.

Finally, section six enables the user to provide information on planned retrofit measures: year of retrofit, amount of investment, achieved reduction of energy consumption (default values), as well as the embodied carbon related to the retrofit action. One core feature of the CRREM tool is the assessment of retrofit actions and their effect on the GHG emissions of a property, so that the user can simulate "virtual" retrofit decisions. Details will be outlined in Section 6.

Information on the purpose of the different variables can be found in the CRREM Risk Assessment Reference Guide (CRREM, Carbon Risk Real Estate Monitor, 2020a). Additionally, to account for different units, the tool comes with a unit converter enabling its users to convert various energy, weight/mass, and volume metrics directly within the tool.

\section{Risk assessment results}

After entering all necessary data, the tool calculates each asset's baseline emissions, as well as the climate and grid-corrected asset performance over time (in terms of GHG intensity per square metre $\left[\mathrm{kgCO}_{2} \mathrm{e} / \mathrm{m}^{2} / \mathrm{a}\right]$ ). The intensity of this particular asset is mapped against the CRREM-derived building-type and location-specific decarbonisation pathway. Net present costs of excess emissions subtracted from the net present value of emissions below the target is referred to as the climate value at risk.

If the emissions exceed the decarbonisation pathway at some point, the tool will display the year of stranding and calculate the excess emissions. To avoid building-specific bias

\section{Net energy demand}

Procured energy - Exported energy

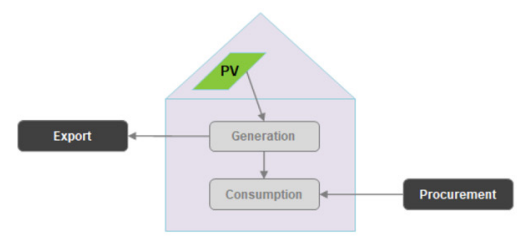

Source: CRREM
Consumed energy - (On-site) Generated energy

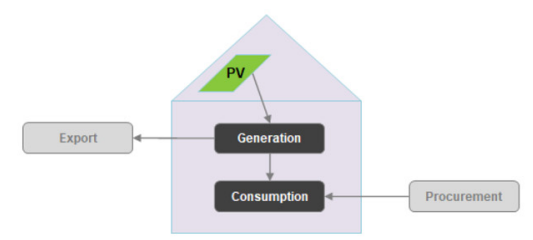

Figure 6.

Definition of net energy demand 
regarding the emission data caused by vacant areas, as well as partial or incomplete reporting periods, the CRREM tool will carry out normalisation calculations.

\subsection{Stranding risk analysis on asset level}

The results for single assets are displayed in a stranding diagram (Figure 7) in the asset sheet. Users can use the drop-down list to switch between different assets (based on the asset IDs) and select either the $1.5^{\circ}$ or $2^{\circ} \mathrm{C}$ target as a basis for the stranding-risk assessment. Next to the stranding diagram, the user can once again see the relevant GHG intensity targets for the selected building. Any subsequent emission above the permissible values of the selected pathway (so-called "excess emissions") are used as one of the risk indicators. The economic obsolescence is associated with the stranding date; the higher the excess emissions, the greater the probability of economic obsolescence. The CRREM follows the approach that properties with low energy efficiency and correspondingly high carbon emissions will also face decreased marketability.

As mentioned above, the tool further enables simulating retrofit measures (see Section 5 for the required input data). If valid data is entered, the tool provides an additional graph displaying the carbon intensity with and without retrofit measures (Figure 8), visualising the new point of stranding. If the building is underperforming, only appropriate retrofit measures can reduce the GHG emissions, ensuring that the building will meet future emission ceilings. However, the potential effects of climate change with regard to future socalled heating- and cooling-degree days (HDD/CDD) and the electricity gird decarbonisation are per se independent of any retrofit measurement. The tool enables the input of one future retrofit scenario, displaying the analysis of emission budget depletion, economic and ecological payback. Besides asset underperformance, the strategic timing of retrofit actions should also be subject to the refurbishment cycle (exploitation of possible synergy effects), availability and the timing of future sales (if intended).

Additionally, the CRREM analysis offers an estimation of future energy consumption (in relation to the property area) and the costs needed to cover energy demand (electricity and fuels), based on estimates of the future heating and cooling requirements of the property (Figure 9). An estimate of the investments required to achieve the decarbonisation targets in energy-efficiency measures round off the analysis at the property level. If the excess emissions are multiplied by a carbon price $\left(€ / \mathrm{kgCO}_{2} \mathrm{e}\right)$, this results in increasing costs due the growing decarbonisation requirements, enabling estimates of imminent financial damage. A further risk indicator based on the GAV is the calculation of the net present value (NPV) of these future cash flows (so-called "Carbon Value at Risk"; CVaR). The CVaR enables a comparison of the stranding risks of multiple assets.

\subsection{Stranding risk analysis at portfolio level}

Besides analysing the carbon performance of single assets, the tool also enables an aggregated (graphical and tabular) view of the above-mentioned risk ratios including CVaR and all stranding events of each asset over time. These results are displayed as the share of stranded assets diagram (see Figure 10) in the portfolio sheet. The calculation of shares can either be based on GAV, gross floor area or simply the number of buildings. Moreover, the user can filter the portfolio assessment in terms of country, property type, entity and assessment year against the chosen climate target.

On an optional basis, the effect of a sale of individual properties at a certain point in time can also be analysed. The CRREM tool portfolio assessment accounts for this fact by providing users with the option to select the year in which they want to sell the asset. Subsequently, the selected assets will not be taken into further consideration.
Carbon risk real estate monitor

289 


\section{JERER}

13,3

Figure 7.

Asset-level stranding analysis against the $1.5^{\circ} \mathrm{C}$ decarbonisation target
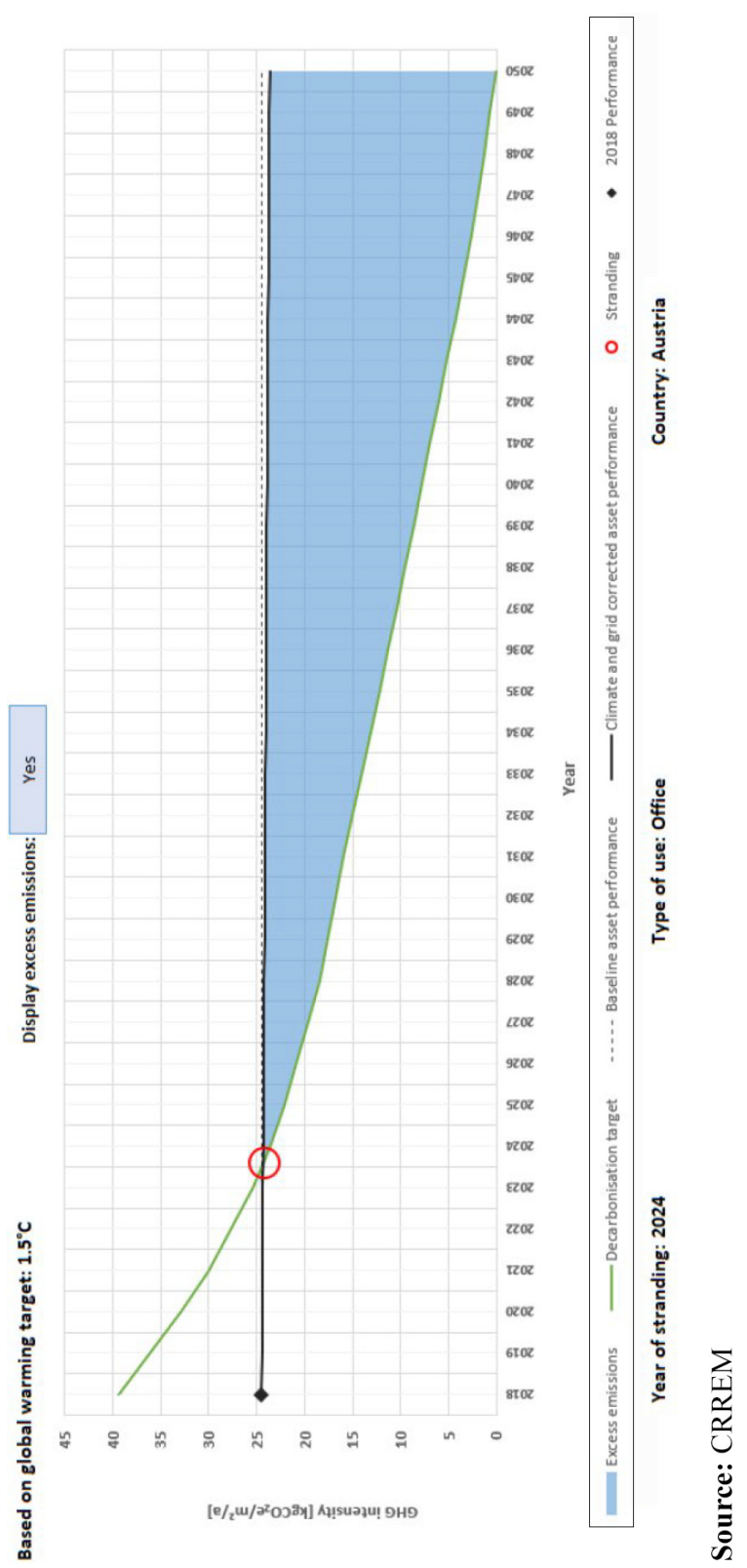
Carbon risk

real estate

monitor

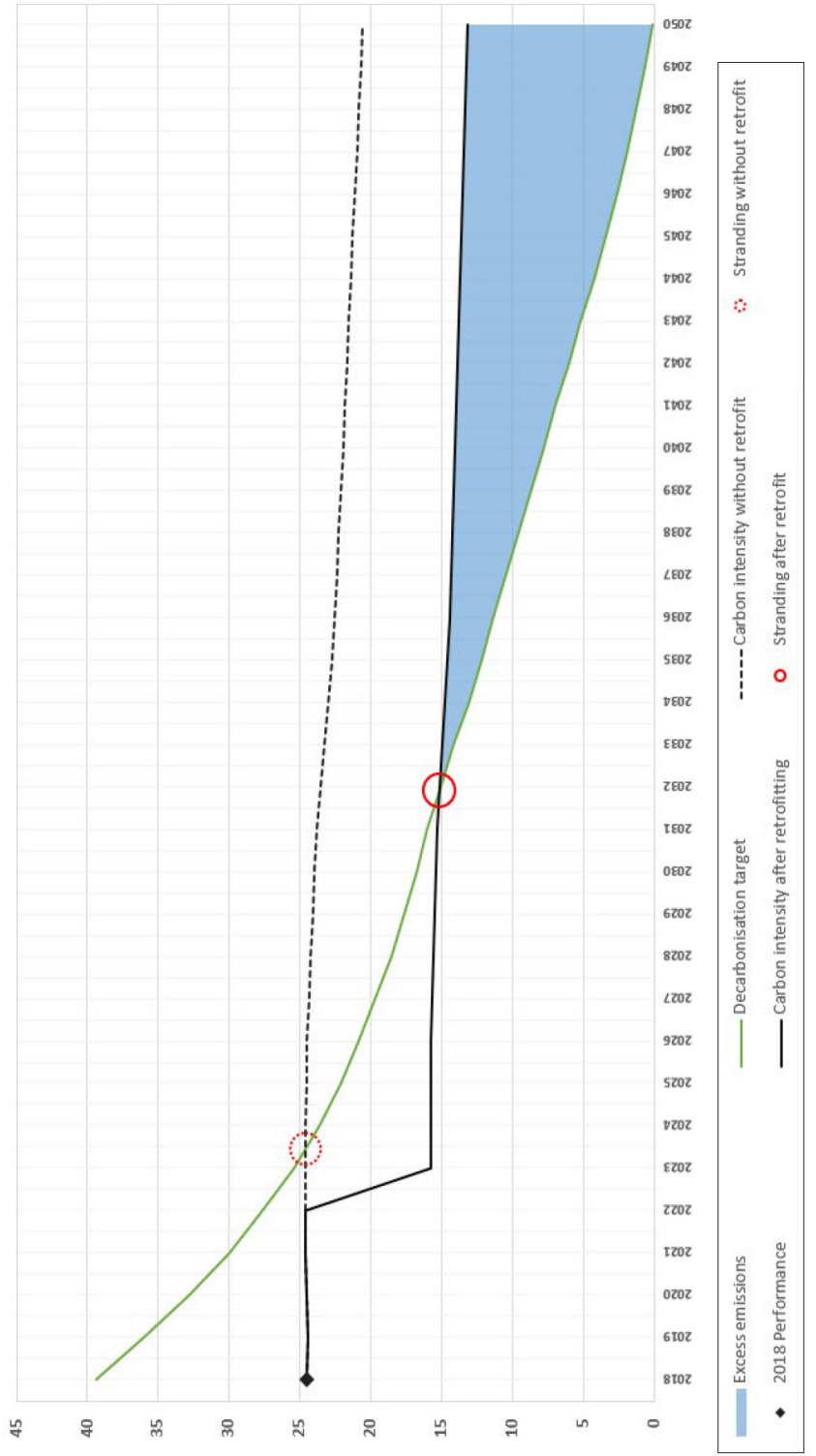

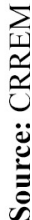

291

Figure 8.

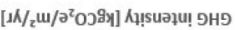
Asset-level stranding analysis with planned retrofits 


\section{JERER}

13,3

\section{2}

Figure 9.

Cost of excess emissions analysis

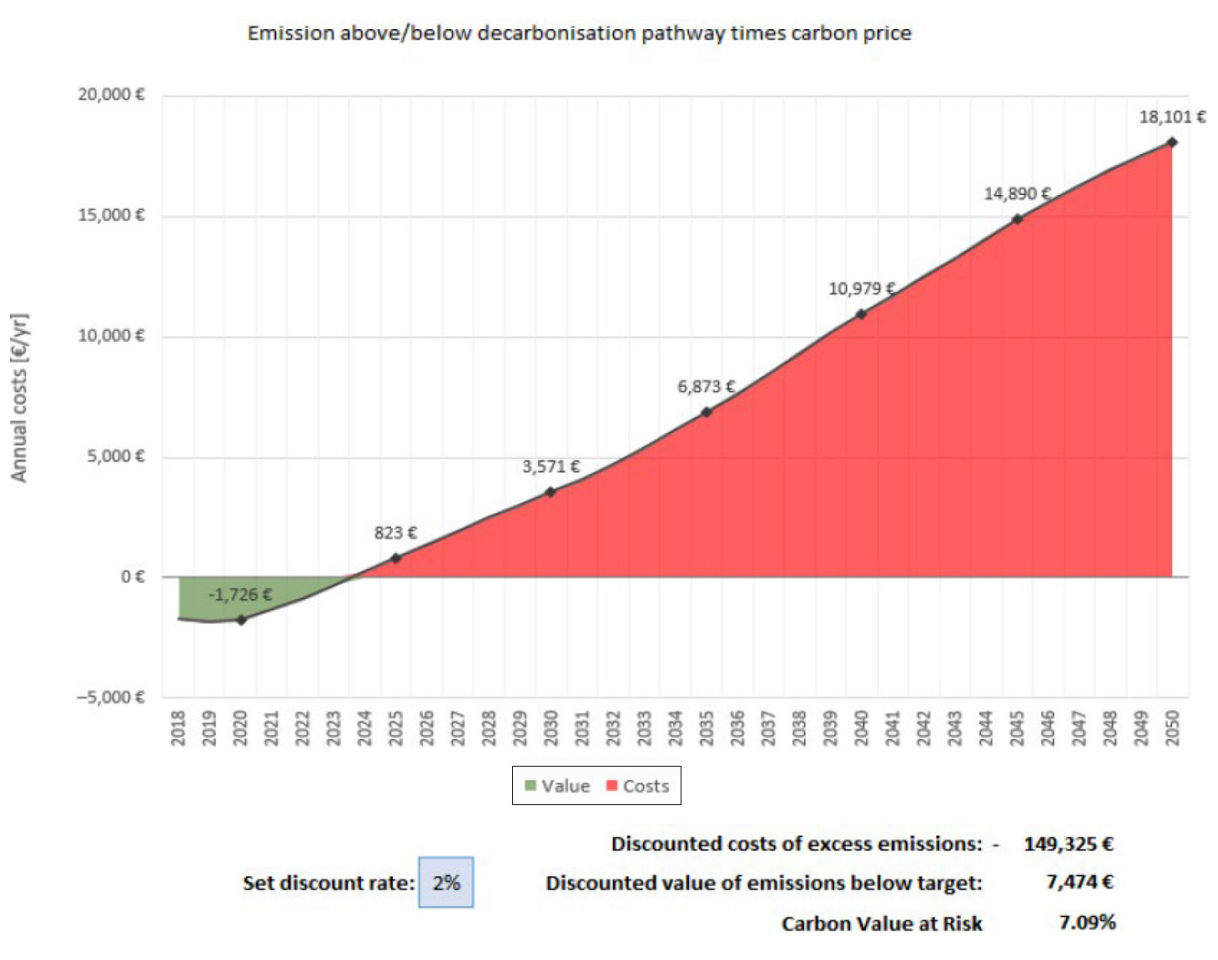

\section{Source: CRREM}

Further analysis includes the average portfolio GHG- and energy-intensity benchmarked against the $1.5^{\circ} \mathrm{C}$ and $2^{\circ} \mathrm{C}$ decarbonisation targets (Figure 11) with and without retrofit scenarios, so as to illustrate the scale of impact of retrofit investments on the portfolio's exposure to stranding. The aggregated costs of excess emissions of all assets within a selected portfolio are displayed. Lastly, a portfolio summary is provided in a tabular format including an overview of the stranding year, discounted costs of excess emissions, cumulated excess emissions and the respective emission budget until 2050.

\subsection{User-specific assumptions}

In addition, the CRREM tool enables the input of one's own assumptions, including the input of user-defined decarbonisation pathways which enables the user to enter individual decarbonisation pathways and emission factors for each asset. Default values can be altered to allow for one's own assumptions and more user-specific input. The user has the option to change the asset-level settings to normalise consumption data to $100 \%$ occupancy and to normalise the weather by normalising current heating- and cooling-degree days. Further climate-change projection can be selected, changing future climate projections and affecting the future heating and cooling demand. The Representative Concentration Pathway (RCP) is a GHG concentration trajectory adopted by the Intergovernmental Panel on Climate Change (IPCC). The RCP8.5 projects a steep incline in $\mathrm{GHG}$ concentration of over $1200 \mathrm{ppm}$ of $\mathrm{CO}_{2}$ equivalents, while the RCP4.5 estimates a moderate inclusion of $650 \mathrm{ppm} \mathrm{CO}_{2}$-equivalents 


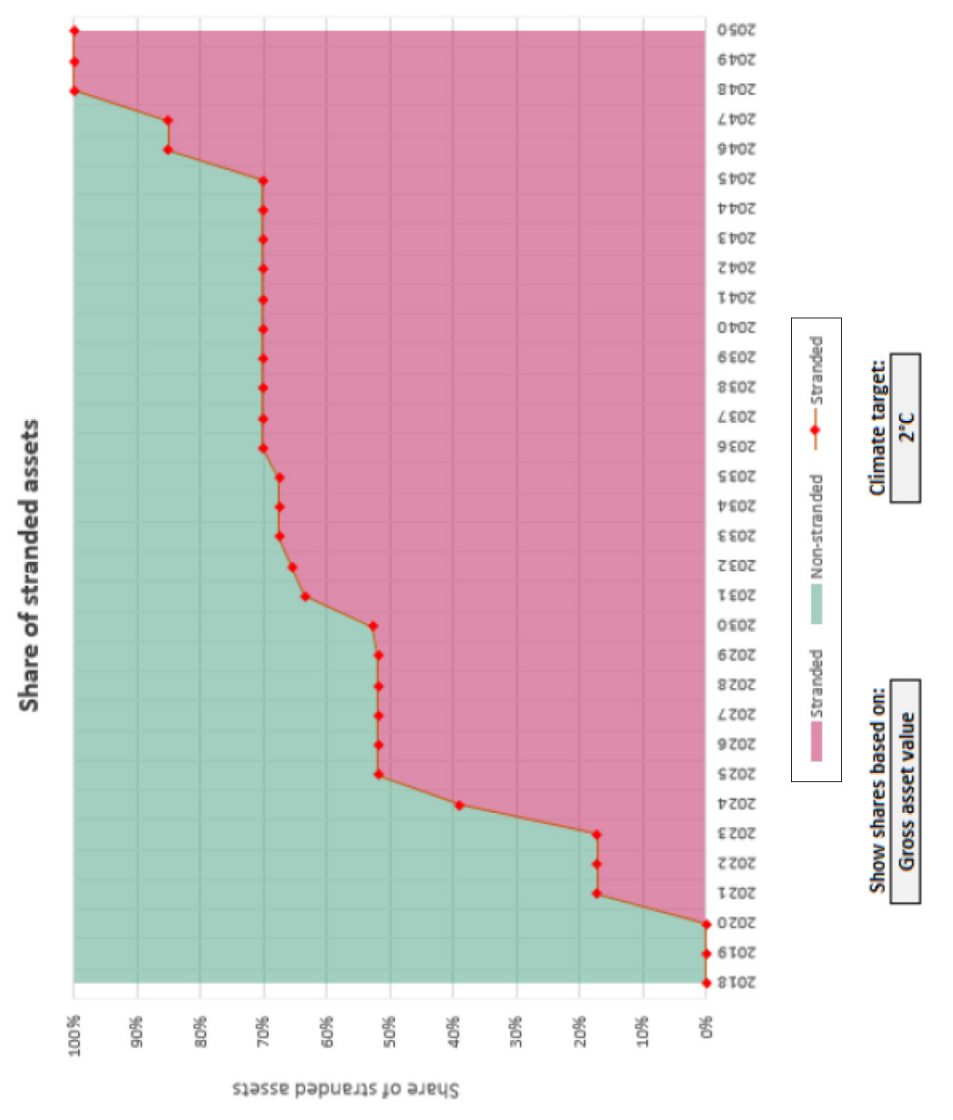

Carbon risk real estate monitor

293
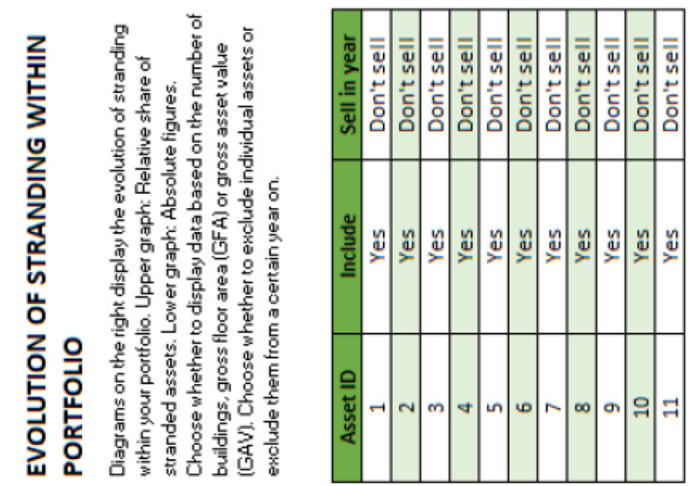

Figure 10.

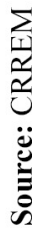
CRREM portfolio analysis; development of the proportion of stranded assets based on GAV 
JERER

13,3

294

Figure 11

Portfolio alignment with the Paris targets
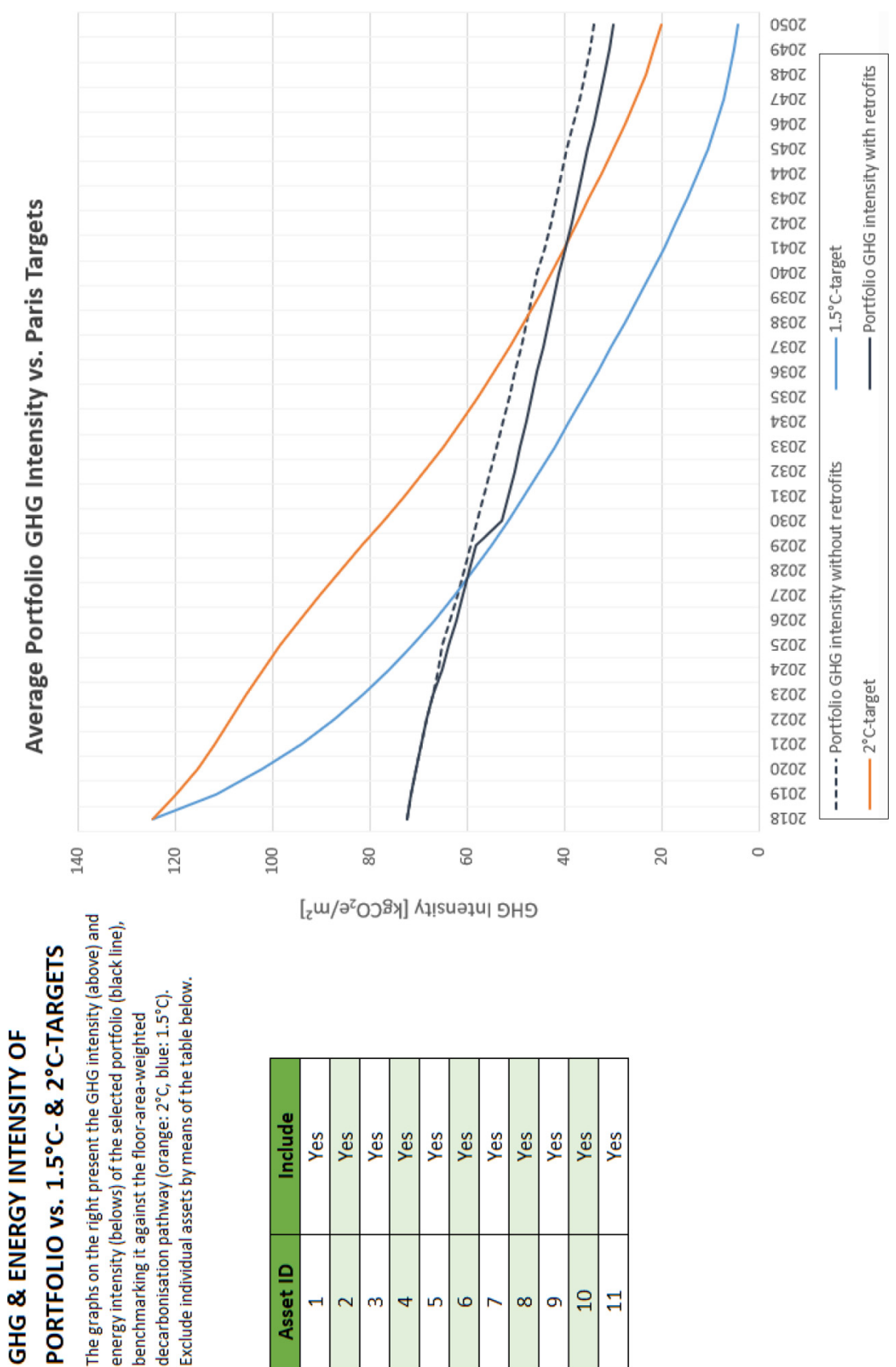
until 2100 (Moss et al., 2010). Additional assumptions include the possibility of setting one's own (constant) emission factors for electricity, district heating and district cooling. Lastly, the user can define and enter his own energy and carbon prices, the annual rate of change as well as altering the discount rate for valuing future expenditure and saving (default: $2 \%$ ).

Furthermore, the tool enables advanced users to set user-defined electricity emission factors for each year, user-defined energy prices for electricity, gas heating and cooling for each year, as well as user-defined decarbonisation pathways (more or less restrictive). However, we recommend caution in the use of these options, as especially less restrictive decarbonisation pathways might severely bias the risk assessment.

Following the idea of a transparent tool, all calculations are carried out in the back-end sheet, enabling users to easily understand the structure. All entered property data and the corresponding results can be saved as a regular excel (.xlsx) file.

\section{Conclusion and outlook}

Ongoing climate change and the accompanying regulatory efforts jeopardise the business viability of real estate companies. However, existing research focusses mainly on the upsides of climate change in terms of higher rents, sales prices or lower operating costs instead of downside risks. When downside risks are in fact assessed, the predominant focus has been - up to now - especially on natural hazards and extreme weather events.

By contrast, decarbonisation in terms of the $1.5^{\circ} / 2^{\circ} \mathrm{C}$ targets, carbon assessment and stranding risks have so far not received any significant research attention, leading to a persistent lack of information availability and transparency, as well as uncertainty in the real estate sector.

Existing tools for the assessment of carbon intensity focus solely on current emissions instead of providing specific decarbonisation pathways, or are methodologically unsound and/or limited in scope, as they, for example, consider few or no different assets classes and often do not distinguish between different geographical locations.

The examined approaches did not cover all relevant emission sources, only accounting for selected building features, are partially limited to one asset instead of providing the possibility to assess whole portfolios and have not achieved broad market acceptance.

With CRREM, we have not only defined principles for a carbon assessment instrument but developed a suitable tool for the assessment of carbon risks.

To the best of our knowledge, CRREM is the first and only tool which provides locationand building-type specific science-based decarbonisation pathways, thereby enabling institutional investors and other stakeholders to start assessing their properties and portfolios in terms of carbon intensity and stranding risks.

As a result, CRREM overcomes the lack of information and transparency in the commercial real estate industry, making carbon risks measurable and thereby triggering retrofit activities.

To ensure a broad market acceptance and high-quality standards, a broad partnership consisting of various stakeholders including institutional investors, asset managers and other corporate partners, as well as industry bodies and scientists, accompanied the development of the tool and tested the pilot version of CRREM under real conditions.

Numerous large international real estate investors have tested the tool, which resulted in over four million square metres in lettable space being analysed during the pilot phase.

Up to now, the focus of $C R R E M$ has been limited to the commercial real estate sector in countries of the European Union only, but by deriving further decarbonisation pathways for non-European countries (incl. the United States, Japan, Singapore and many other important
Carbon risk real estate monitor 
JERER 13,3

investment locations), a first step towards a global roll-out has already been made. Furthermore, additional pathways for residential properties have been derived, enabling a broader use of the tool.

The implications for different stakeholders are as follows. Both for institutional investors and asset managers as well as other stakeholders, the tool provides a suitable basis for investment decision-making. The tool accounts for different locations as well as buildingand usage-type specific features.

All in all, CRREM provides a valuable basis for assessing carbon intensity and the assessment of stranding risks, providing appropriate guidance for the decarbonisation of the commercial real estate industry.

\section{Acknowledgements}

The authors are grateful to members of the CRREM European Investor Committee (CRREM EIC) for their scientific support and advice. They also express their appreciation to APG Asset Management (Derk Welling, Senior Responsible Investment and Governance Specialist), PGGM (Mathieu Elshout, Senior Director, Private Real Estate Europe and Stan Bertram, Junior Investment Manager, Private Real Estate), Norges Bank Investment Management (Christopher Wright, Sustainability Manager, Real Asset Risk), GPIF (Hiroyuki Yabe, Director, Private Market Investment Department) and Ivanhoé Cambridge (Stéphane Villemain, Vice President, Corporate Social Responsibility and Rob Simpson, Director Sustainability) for supporting the derivation of further decarbonisation targets for non-EU countries, which can be downloaded via crrem.org/pathways/.

This project has received funding from the European Union's Horizon 2020 research and innovation program under grant agreement no. 785058. The authors, as well as the consortium as a whole much appreciate this support. The CRREM consortium consists of five well-known institutions from various European countries, all with many years of experience in the field of energy efficiency and carbon research: IIÖ Institute for Real Estate economics (Austria, project coordinator), University of Alicante (Spain), Ulster University (United Kingdom), GRESB (Netherlands), and Tilburg University's TIAS Business School (Netherlands).

\section{Notes}

1. See Bienert et al. (2016) for a meta-study of more than 70 green-pay off studies worldwide.

2. Ongoing climate change might lead to a shift in HDD and CDD, leading to a shift in heating and cooling demand at various locations. We apply the climate model data of Spinoni et al. (2018) to the future development of heating- and cooling-degree days (HDD/CDD) (Day, 2006), to cover the effect of climate change on the development of future heating- and cooling-degree days (see upper dashed line in Figure 1).

3. IPMS refers to the "International Property Measurement Standards" developed by a group of professionals and organisations, including the Royal Institution of Chartered Surveyors (RICS).

\section{References}

Balica, S.F., Wright, N.G. and van der Meulen, F. (2012), "A flood vulnerability index for coastal cities and its use in assessing climate change impacts", Natural Hazards, Vol. 64 No. 1, pp. 73-105.

Bienert, S. (2014), Extreme Weather Events and Property Values: Assessing New Investment Frameworks for the Decades Ahead, Urban Land Institute, London. 
Bienert, S. (2016), Climate Change Implications for Real Estate Portfolio Allocation: Industry Perspectives, Urban Land Institute, London.

Bienert, S., Ansari, N. and Geiger, P. (2016), Metastudie, Nachhaltigkeit Contra Rendite? Die Implikationen Nachhaltigen Wirtschaftens Für Offene Immobilienfonds Am Beispiel Der Deka Immobilien Investment GmbH Und Der WestInvest GmbH, IRE|BS International Real Estate Business School, Universität Regensburg, Regensburg.

Bouwer, L.M. (2010), "Disasters and climate change: analyses and methods for projecting future losses from extreme weather", available at: www.researchgate.net/publication/ 241866932_Disasters_and_climate_change_analyses_and_methods_for_projecting_ future_losses_from_extreme_weather/link/55b6315208ae9289a08aac5f/download (accessed 27th May 2020).

Bundesministerium für Wirtschaft und Energie (BMWi) (2015), "Energieeffizienzstrategie gebäude", available at: www.bmwi.de/Redaktion/DE/Publikationen/Energie/energieeffizienzstrategiegebaeude.pdf?_blob=publicationFile\&v=25 (accessed 28th May 2020).

Caldecott, B., Dericks, G., Pfeiffer, A. and Astudillo, P. (2017), "Stranded Assets: the Transition to a Low Carbon Economy. Overview for the Insurance Industry. Innovation Series: Society and Security. Emerging Risk Report 2017”, Lloyd's of London, London.

Caldecott, B. (2018a), Stranded Assets and the Environment: Risk, Resilience and Opportunity, Abingdon-on-Thames, Routledge.

Caldecott, B. (2018b), Stranded Assets: Development in Finance and Investment, Abingdon-on-Thames, Routledge.

CDP Carbon Disclosure Project, UN Global Impact, World Resources Institute, WWF (2015), "Sectoral decarbonization approach (SDA): a method for setting corporate emission reduction targets in line with climate science", available at: https://d306pr3pise04h.cloudfront.net/docs/publications \%2FSectoral-Decarbonization-Approach-Report.pdf (accessed 27th May 2020).

Christensen, P.H., Robinson, S.J. and Simons, R.A. (2018), "The Influence of Energy Considerations on Decision Making by Institutional Real Estate Owners in the U.S." Renewable and Sustainable Energy Reviews, Vol. 94, pp. 275-284.

Conyers, Z.A., Grant, R. and Roy, S.S. (2019), "Sea level rise in Miami beach: vulnerability and real estate exposure", The Professional Geographer, Vol. 71 No. 2, pp. 278-291.

CRREM, Carbon Risk Real Estate Monitor (2020a), "CRREM risk assessment reference guide", available at: www.crrem.eu/wp-content/uploads/2020/02/CRREM-Risk-Assessment-ReferenceGuide-2020-02-12.pdf (accessed 25th May 2020).

CRREM, Carbon Risk Real Estate Monitor (2020b), "From global emission budgets to decarbonisation pathways at property level: CRREM downscaling and carbon performance assessment methodology", available at: www.crrem.org/pathways (accessed 30 May 2020).

Day, T. (2006), "Degree-days: Theory and application", The Chartered Institution of Building Services Engineers, London.

DENEFF Deutsche Unternehmensinitiative Energieeffizienz, Finanzforum Energieeffizienz (2020), "Vorstellung des Carbon Value Analyser", available at: www.finanzforum-energieeffizienz.de/ fileadmin/downloads/Einf\%C3\%BChrung_in_den_Carbon_Value_Analyser.pdf (accessed 25th May 2020).

Eichholtz, P., Kok, N. and Quigley, J.M. (2009), "Why companies rent green: CSR and the role of real estate", Academy of Management Annual Meeting Proceedings, 2009.

Eichholtz, P., Kok, N. and Quigley, J.M. (2010), "Doing well by doing good? Green office buildings", American Economic Review, Vol. 100 No. 5, pp. 2492-2509.

Freybote, J., Sun, H. and Yang, X. (2015), "The impact of LEED neighborhood certification on condo prices", Real Estate Economics, Vol. 43 No. 3, pp. 586-608.

Carbon risk real estate monitor

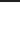

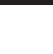




\section{JERER 13,3}

Fuerst, F. and Mc. Allister, P. (2011a), "Green noise or green value? Measuring the effects of environmental certification on office values", Real Estate Economics, Vol. 39 No. 1, pp. 45-69.

Fuerst, F. and Mc. Allister, P. (2011b), "Eco-labeling in commercial office markets: do LEED and energy star offices obtain multiple premiums?”, Ecological Economics, Vol. 70 No. 6, pp. 1220-1230.

Gasper, R., Blohm, A. and Ruth, M. (2011), "Social and economic impacts of climate change on the urban environment", Current Opinion in Environmental Sustainability, Vol. 3 No. 3, pp. 150-157.

Hallegatte, S., Green, C., Nicholls, R.J., J. and Corfee-Morlot, J. (2013), "Future flood losses in major coastal cities", Nature Climate Change, Vol. 3 No. 9, pp. 802-806.

Hallegatte, S., Ranger, N., Mestre, O., Dumas, P., Corfee-Morlot, J., Herweijer, C. and Wood, R.M. (2011), "Assessing climate change impacts, sea level rise and storm surge risk in port cities: a case study on Copenhagen", Climatic Change, Vol. 104 No. 1, pp. 113-137.

Haran, M., McGreal, S., Davis, P., McCord, M., Berry, J., Lo, D., Hirsch, J., Lafuente, J.J., Recourt, R., Spanner, M., Geiger, P., Taltavull, P., Perez, R., Juárez, F., Martinez, A.M. and Brounen, D. (2019), "Carbon risk integration in corporate strategies within the real estate sector", CRREM report No. 2", Wörgl, Austria.

HES Hotel Energy Solutions (2011), "HES E-Toolkit user manual, energy efficiency and renewable energy applications in the hotel sector", available at: www.e-unwto.org/doi/pdf/10.18111/ 9789284415120 (accessed 24th May 2020).

Hirsch, J., Braun, T. and Bienert, S. (2015), "assessment of climatic risks for real estate", Property Management, Vol. 33 No. 5, pp. 494-518.

Hui, E., Chan, E. and Yu, K. (2015), "The effect of LEED certification on Shanghai's prime office rental value", Journal of Facilities Management, Vol. 13 No. 3, pp. 297-310.

INREV, EPRA (2016), "Real estate in the real economy", available at: www.epra.com/media/ INREV_EPRA_Real_Estate_Real_Economy_2016_Report_1466582653897.pdf (accessed 27th of May 2020).

INREV, EPRA (2018), "Real estate in the real economy - 2018", available at: www.inrev.org/system/ files/2019-04/INREV-EPRA-Real-Estate-Real_Economy_2018_Report.pdf (accessed 27th of May 2020).

ITP, International Tourism Partnership (2016), "Hotel water measurement initiative (HWMI) methodology v1.0", available at: www.tourismpartnership.org/resources/ (accessed 24th of May 2020).

Kok, N. and Jennen, M. (2012), "The impact of energy labels and accessibility on office rents", Energy Policy, Vol. 46, pp. 489-497.

McAlpine, S.A. and Porter, J.R. (2018), "Estimating recent local impacts of Sea-Level rise on current Real-Estate losses: a housing market case study in Miami-Date, Florida", Population Research and Policy Review, Vol. 37 No. 6, pp. 871-895.

Moss, R.H., Edmonds, J.A., Hibbard, K.A., Manning, M.R., Rose, S.K., van Vuuren, D.P., Carter, T.R., Emori, S., Kainuma, M., Kram, T., Meehl, G.A., Mitchell, J.F.B., Nakicenovic, N., Riahi, K., Smith, S.J., Stouffer, R.J., Thomson, A.M., Weyant, J.P. and Wilbank, T.J. (2010), "The next generation of scenarios for climate change research and assessment”, Nature, Vol. 463 No. 7282, pp. 747-756. doi: $10.1038 /$ nature08823.

Robinson, S., Simons, R., Lee, E. and Kern, A. (2016a), "Demand for green buildings: Office tenants' willingness-to-Pay for green features”, Journal of Real Estate Research, Vol. 38 No. 3, pp. 423-452.

Robinson, S., Singh, A.J. and Das, P. (2016b), "Financial impact of LEED and energy star certifications on hotel revenues", The Journal of Hospitality Financial Management, Vol. 24 No. 2, pp. 110-126.

Spinoni, J., Vogt, J.V., Barbosa, P., Dosio, A., McCormick, N., Bigano, A. and Füssel, H.M. (2018), "Changes of heating and cooling Degree-Days in Europe from 1981 to 2100", International Journal of Climatology, Vol. 38 No. 1, pp. 191-208. 
Suh, M.J., Pearce, A.R., Song, Y., Kwak, Y.H., Kim, J.I. and Zhang, Y. (2019), “The impact of LEEDEnergy star certified office buildings on the market value of adjoining buildings in New York city", Journal of Green Building, Vol. 14 No. 1, pp. 31-52.

UNEP United Nations Environmental Program (2016), "The Emissions Gap Report 2016: A UNEP Synthesis Report", UNEP, Nairobi.

UN-FCCC United Nations Framework Convention on Climate Change (2016), "The Paris agreement".

UN Environment and International Energy Agency (2017), "Towards a zero-emission, efficient, and resilient buildings and construction sector - Global status report 2017", available at: www. worldgbc.org/sites/default/files/UNEP\%20188_GABC_en\%20\%28web\%29.pdf (accessed 30 May 2020).

Walsh, P., Griffiths, C., Guignet, D. and Klemich, H. (2019), “Adaptation, sea level rise, and property prices in the Chesapeake Bay watershed”, Land Economics, Vol. 95 No. 1, pp. 19-34.

WTTC, ITP - World Travel and Tourism Council, International Tourism Partnership (2016), "Hotel carbon measurement initiative v.1.1 methodology (December 2016)", available at: www. tourismpartnership.org/resources/ (accessed 24th May 2020).

\section{Further reading}

Directive (EU) (2018), "844 Of the European parliament and of the council of 30 may 2018 amending directive 2010/31/EU on the energy performance of buildings and directive 2012/27/EU on energy efficiency", PE/4/2018/REV/1, available at: https://eur-lex.europa.eu/eli/dir/2018/844/oj (accessed 29th of May 2020).

\section{Corresponding author}

Maximilian M. Spanner can be contacted at: maximilian.spanner@iioe.at

For instructions on how to order reprints of this article, please visit our website: 